\title{
IT Service Level Management: Practices in Large Organizations
}

\author{
Gianmario Motta ${ }^{1}$, Thiago Barroero ${ }^{1}$, Filippo Galvani ${ }^{1}$ and Antonella Longo ${ }^{2}$ \\ 1University of Pavia, Pavia, Italy \\ 2University of Salento, Lecce, Italy
}

\begin{abstract}
We survey actual practices of IT SLM (Service Level Management) in large organizations. The survey is based on a comprehensive analysis framework, called ESLAM (Extended Service Level Analysis Model) that considers (a) service level variables, that are what SLM measures (b) service information system, that processes information on service level technology, and (c) service organization that defines roles and procedures to run SLM. The survey was based on face to face interviews to both IT intensive (Banks and Telcos) and non-intensive (as Railways) organizations and has considered also context variables, as size and organizational shape, to develop correlation analysis. The survey has identified key drivers of SLM maturity and shown that IT intensive organizations, as banks and telecommunications, develop a more mature SLM. Also SLM maturity is unrelated to organizational size.
\end{abstract}

Keywords: Service Level, Service Level Management, IT management, IT governance, ITIL

\section{Introduction}

\section{The Service Level Management issue}

IT Service Level Management (SLM) is the process through which IT Service Levels are planned, monitored and controlled, namely the classic Anthony's cycle (Anthony, R.A., 1966). SLM covers all phases of the IT system lifecycle, from the analysis of user needs to the software development activities and, finally, to operations.

With the growing pervasiveness of computing, IT Service Level is a key in corporations. IT Service Level measures the quality provided by IT services, e.g. the response time of a web ticketing system. IT Service Level (Lewis, L., 1999) is a structural element of Service Level Agreements (SLA), that state service levels expected against a given fee (Buco, M.J., 2002; Hiles, A.N. et al., 1994; Raimondi, F. et al., 2008; Winniford, M.A. et al., 2009). SLA are used by companies to define contracts with outsourcers and, increasingly, to define also service levels of the IT department.

In a typical corporation you find a variety of SLA. The IT corporate department issues SLA for the panoply of services supplied to corporate user departments. These SLA may contain in turn services and related SLA of outsourcers, e.g. an IT department may provide web ticketing services, composed by network services supplied by telecom operators, a front-end portal run by a software provider and, finally, a home made backend software. So, a simple software application may imply several SLA and,

Copyright (C) 2011 Gianmario Motta, Thiago Barroero, Filippo Galvani and Antonella Longo. This is an open access article distributed under the Creative Commons Attribution License unported 3.0, which permits nrestricted use, distribution, and reproduction in any medium, provided that original work is properly cited. Contact author: Gianmario Motta E-mail: gianmario.motta@unipv.it, 
moreover, the final service level to the end users may result from many intertwined service elements, that include network, server, software and alike.

\section{Our Research}

Our research has two main objectives:

1. To define a complete SLM framework to address the business impact of IT services

\section{To assess SLM best practices}

The most challenging issue of the first step was the measure of the IT service level on Long Running Processes (LRP), i.e. complex processes made of several activities and with a variety of stakeholders. For instance, the "freight train composition" LRP involves Freight Division and Track Division and, also, Sales Offices and End Customers, who are interested in the service level of the whole business process (Motta, 2010). As a result of the first step, we developed a SLM framework, called ESLAM -Extended Service Level Analysis Model- (Barroero, T. et al., 2010; Motta, G. et al., 2010), that extends some well known IT management frameworks, as ITIL (Aib, I. et al., 2006; Bartolini, C. et al., 2009; Case, G., 2007; Diao, Y. et al., 2008; Schaaf, T., 2007; Toleman, M. et al., 2009), COBIT (IT Governance Institute, 2007; Ribeiro, J. et al., 2009), MOF (Microsoft, 2008), HP Service Management Framework (Soward, K. et al., 2007) and also CA's maturity framework (Logan, J.C., 2008). The extension entails a wider view of SLM, that includes (a) the service variables/metrics to be measured by SLM, (b) the organizational framework of roles and procedures to run SLM, and (c) the information systems that (i) capture performance data, (ii) calculate service performances and (iii) report information to managers (Schaaf, T. et al., 2008).
As a second step we surveyed SLM practices in Europe and Far East. This paper specifically deals with the survey and related issues. The first section explains the reference grid we used to map actual practices. The following sections illustrate the method and main findings of the survey. A final section draws conclusions and motivates future research.

\section{The Survey Grid}

The survey grid was based the reference framework that was developed in the first research step, called ESLAM (Extended Service Analysis Framework), that is conceived for large corporations (Barroero, T. et al., 2010) and reflects ITIL principles (Menken, I. et al., 2009). Here below we describe its main elements, namely (a) Service Variables, (b) Service Organization, and (c) Service Information system.

\section{Service Variables}

Service variables define what SLM measures. The wider the measurement span, the more mature SLM.

The measurement span may be divided in levels, each one reflecting a different class of IT services. Within each level, measurement span may be defined in terms of measure metrics and measured objects. The higher the number of the metrics and the higher the number of objects measured, the more mature the SLM. In short, within each service level $\mathrm{m}$, the service variables $\mathrm{V}$ are given by the intersection of the set of objects 0 at the level and the set of applicable metrics $M$ of each level, that is lower or equal to Cartesian product (Equation 1).

$$
\sum_{m=1}^{3} V_{m}: V_{m}=\left(O_{m} \cap M_{m}\right) \leq\left(O_{m} \times M_{m}\right)
$$


Let us first illustrate what we mean by "levels". According to ITIL taxonomy (Menken, I. et al., 2009) we identify three levels - IT Technical Services, IT Business Services, Business Processes. IT Technical Services are the lowest level, e.g. an IT provider, which may be an external supplier or a department of the corporation, supplies services e.g. operating a network. These services are not perceived by the end users. Business Services are the intermediate level. They supply a specific application e.g. an airline reservation system that supports a given business process e.g. web seat selling, and directly support business process activities and influence business results. Finally, Business Processes, the highest level, deliver business outcomes, e.g. in the process "Train Composition" of a railway organization "Composed Trains" is a primary outcome.

Business Processes are the most complex level and the most critical to the business impact. For, business process performances reflect the stakeholders' point of view, e.g. timeliness is critical for the end customers, which, by contrast, do not care of the productivity of railways; productivity, in turn, is a key objective of the plant supervisor. Figure 1 shows the stakeholderoriented grid of business process performances (Longo, A. et al., 2006). Specifically, columns list classes of performance (cost, quality, level of service) while rows list classes of stakeholders (manager, customer, worker), and quadrants contain Key Performance Indicators (KPI).

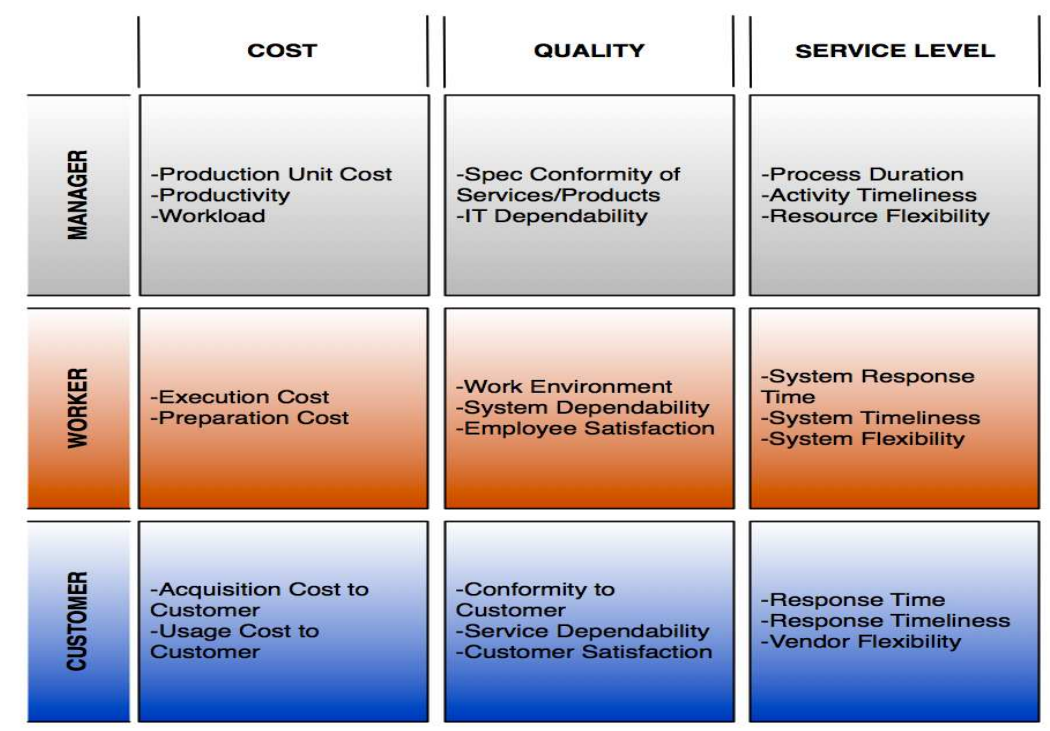

Figure 1 - A Stakeholder Oriented Grid of Business Process Performances (redesigned from Longo, A. et al., 2006)

\section{Service Level Information System}

The reference architecture of the service level information system defines building blocks that cover the whole systems life cycle (Figure 2).The wider the coverage of the reference architecture the more mature the SLM.
Let us comment each building block.

- Project Control (PC) supports the project cycle. It processes service level information related to the project activities, e.g. timeliness, quality and alike. It also generates alarms in front of critical exceptions. It is a 
key point in large organizations with hundreds running initiatives.

- Real Time Monitoring (RTM) collects, typically by probes, performances and status of each object that contributes to technical and business services. It gathers and displays real-time information on components as applications, operating systems, network protocols, and network infrastructure. RTM is a key ingredient of the so called "service control room" where IT people monitor operations that may involve many thousands of components.

- Catalogue and SLA management maintain the catalogue of services along their life cycle, from design to operation and termination. Also they store the relations within and across services levels, e.g. which applications (also called IT business services) support a given business process and which IT services support a given application.

- Management Control (MC) is a business intelligence software that stores and analyses time series of performances, thus supporting planning and periodical control of the performances. The wider the coverage of IT services and business processes, and the span of performances indicators, the more mature the system is. A typical service MC system (a) stores performance data on each application, middleware and hardware, (b) calculates service measures and (c) reports to the appropriate responsible (Schaaf, T. et al., 2008).

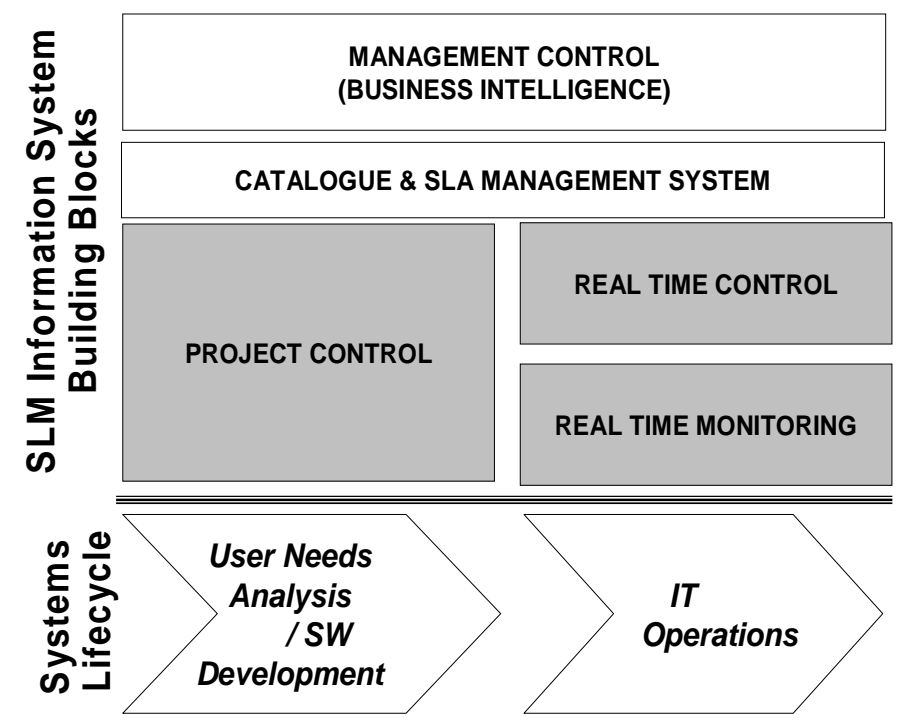

Figure 2 - Building Blocks of the Service level Information System (redesigned from Motta. et al., 2010)

An ideal implementation shall cover the whole ideal architecture. For, real time and project control block enable physical control. In turn, the business intelligence block, with time series and summarized information, enables continuous improvement and benchmarking.

\section{Service Organization}

The organization framework describes an ideal organizational architecture of SLM in terms of business processes, roles, and their relations. Generally, such framework is an extension of ITIL (Rudd, C. et al., 2007). The 
higher the coverage of the reference organization the more mature SLM.

An overview of roles is given in Figure 3 Let us consider them. The Service Level Manager is the core role. Ideally, he or she is an independent position, assures that current and forthcoming services are appropriately profiled, negotiates service levels for Service Level Agreements (SLA), Operational Level Agreements (OLA), Underpinning Contracts (UC), identifies and designs the SLM reporting system, etc. The Service Catalogue Manager maintains the catalogue of IT Business and Technical Services. Other roles are external to the SLM unit, but they are highly involved in the SLM process. E.g. the Capacity \& Performance Manager assures that IT capacity can enable requested service levels while the Security Manager defines security levels and is in charge of Disaster Recovery Plan, and, finally, the Supplier Manager manages technical relations with service providers. Corporate users, e.g. departments or employees, generate and define service level demand at business process level. Finally, Suppliers/Outsourcers provide technical and/or business services according to their agreed SLA, UC and OLA.

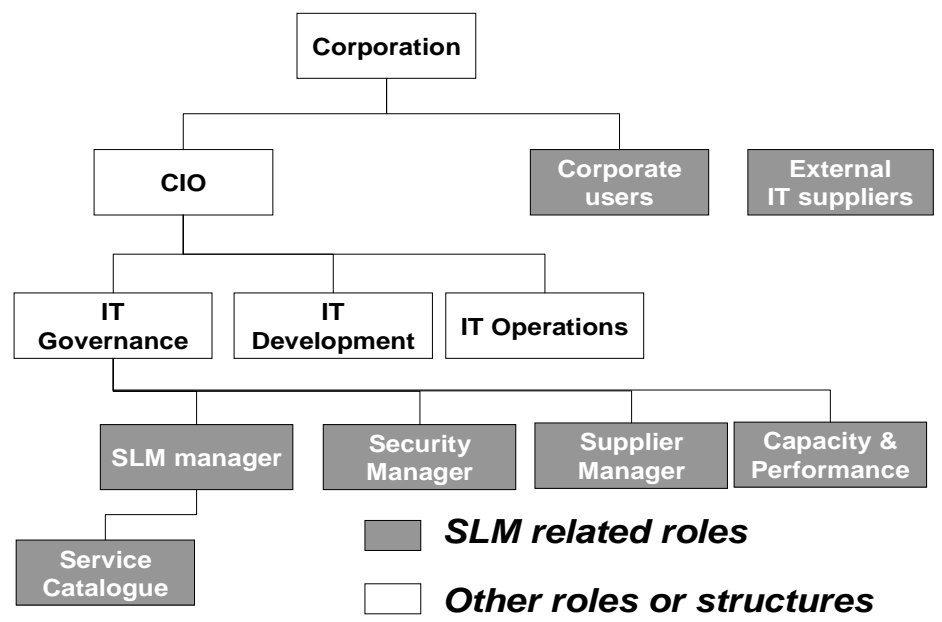

Figure 3 - ESLAM Roles (redesigned from Motta. et al., 2010)

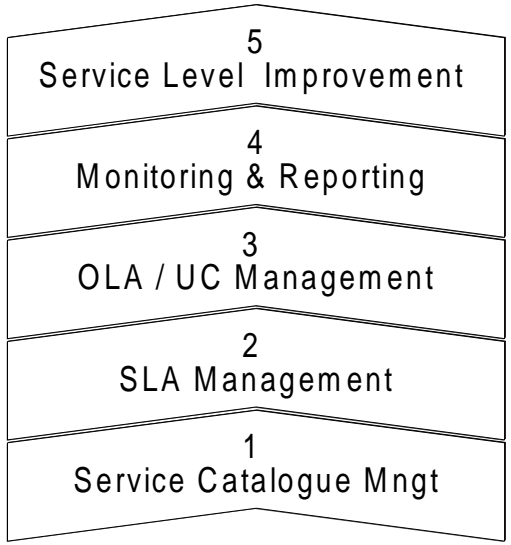

Figure 4 - ESLAM Process Phases (redesigned from Motta. et al., 2010) 
The SLM process framework includes the phases by which SLM is planned, run and improved (Figure 4).Lets us consider each phase. Service Catalogue Management defines and maintains the Service Catalogue that describes all IT Business Services, related SLA and Service Level Objectives (SLO). SLA Management manages the lifecycle of SLAs with actual service providers and related SLOs (Service Level Objectives). OLA/UC Management manages the lifecycle of OLAs, UCs and related performance indicators. Monitoring and Reporting includes definition of reporting policies, service level meetings, and definition of report contents. Finally in
Service Level Improvement are included not only the usual reviews and negotiations with suppliers but also uses periodical benchmarking activities in order to align service levels to the "best of breed".

The RACI (Responsible, Accountable, Consulted, Informed) table (Figure 5) maps the roles on the process phases. You can note that the end users are heavily involved in defining and reviewing service levels, reflecting ESLAM philosophy according which service business outcomes are structural parts of SLM and related SLAs.

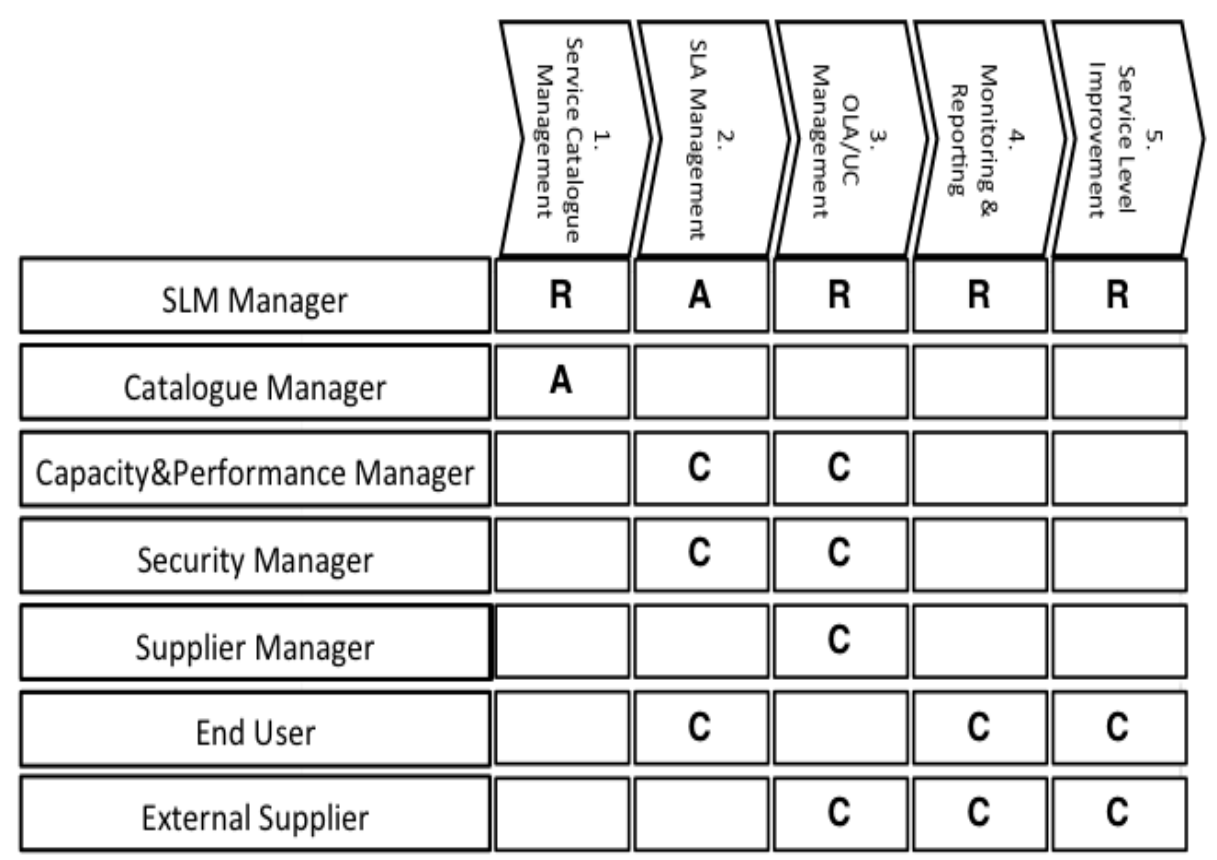

Figure 5 - ESLAM RACI (simplified, redesigned from Motta. et al., 2010)

\section{The Survey Questionnaire}

The survey questionnaire is structured into three sections. Section 1 positions the company, section 2 sketches out the profile of the IT organization, and section 3 assesses SLM profile (Table 1). This structure enables to relate the SLM profile to the organization structure, to the outsourcing options and to other context variables. The survey was performed via face-to-face interviews with the CIOs and/or the manager in charge of service levels, from April to September 2010. 
Table 1 - Summary of the Survey Questionnaire

\begin{tabular}{|l|l|}
\hline $\begin{array}{l}\text { Overall } \\
\text { corporation } \\
\text { profile }\end{array}$ & $\begin{array}{l}\text { General information on the corporation } \\
\text { Institutional information: business models, organization structure, } \\
\text { economic data. }\end{array}$ \\
\hline $\begin{array}{l}\text { IT \& Outsourcing } \\
\text { profile }\end{array}$ & $\begin{array}{l}\text { IT organization: size, mission, role, structure } \\
\text { IT outsourcing monitoring logic }\end{array}$ \\
\hline SLM profile & $\begin{array}{l}\text { SLM technology: architecture of SLM system } \\
\text { SLM history: steps, coverage, benefits strategy: coverage, roles, }\end{array}$ \\
& $\begin{array}{l}\text { relationships, contracts } \\
\text { SLM approach: model of variables and organization } \\
\end{array}$ \\
& SLA/SLO reporting and monitoring \\
\hline
\end{tabular}

\section{The survey sample}

The sample was intended to compare best practices in IT intensive industries with the target industry, i.e. railways. It is represented by T-shape in Figure 6.

The leg includes five firms belonging to transportation industry, i.e. our target. The two arms include IT intensive organizations, respectively Telecommunications and Financial Services. Companies surveyed are listed in Table 2. Let us illustrate them.

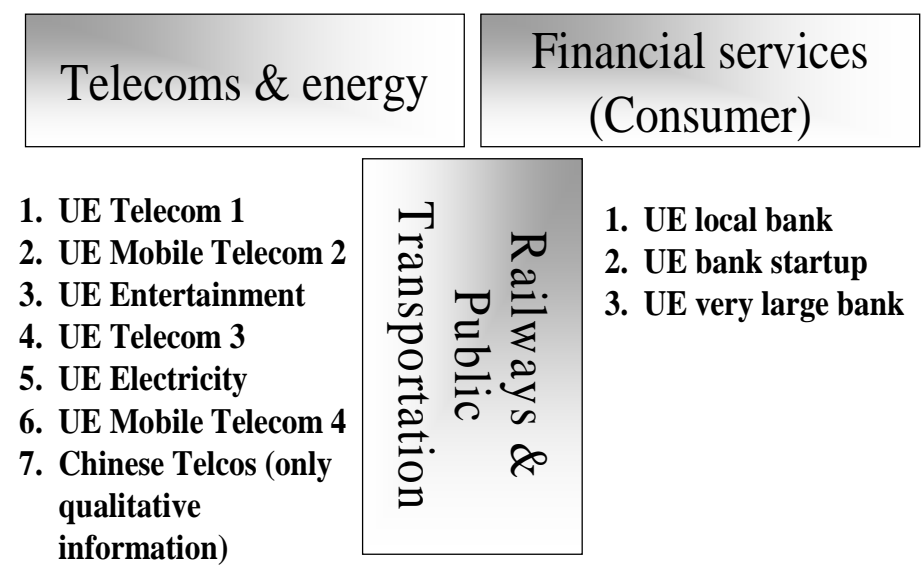
1. Large Airline
2. Municipal Transportation
3. UE Railways 1
4. UE Railways 2 (Parent Company)
5. UE Railways 3 (Track Division)

Figure 6 - T-shaped Sample

In the transportation sample we have considered railways of large European countries. Formerly government owned monopolies, they include the same business units respectively for track, passenger transport, freight transport, stations, services. Systems are critical to manage trains, traffic, ticketing and freight. IT staff may count hundreds of people, and could be decentralized or centralized. To compare 
their practices we have added two organizations of similar industries, namely municipal transportation and airlines. The municipal transportation operates in an urban European area of about 2,5 million people. It is a reference, because of the high performance requirements of IT services to passengers and for real time traffic control. Airlines have been added since they have developed from decades a structured and interoperable IT system.

Telecommunications are intensive users of IT, with their Business Support Systems (BSS) and Operations Support Systems (OSS). BSS support internal transactions and transactions with the customers, such as order, billing and alike. OSS support network operations, such as service provisioning, traffic management and alike. IT staff are very large and may count, in bigger organizations, over 1,000 people, with an IT budget over 1 billion Euro. The high IT complexity requires a robust Service Level Management. Electricity and Entertainment are included in this sample, because of the growing IT role for the business. Also we have considered public information about the three main telecommunications in China that total over 500 million users.

Finally, we have included banking, where IT is part of business. A very large bank should control IT service levels on huge volumes and can be considered as benchmark. A start-up can build its IT and its SLM without ties and therefore can offer best practice. Mid size is a reference of the business practice

Table 2 - Companies Surveyed

\begin{tabular}{|l|c|}
\hline \multicolumn{1}{|c|}{ Company } & Sales (Billion Euro) \\
\hline National Railways 1 & $25+$ \\
\hline National Railways 2 & 8 \\
\hline National Railways 3 & 3 \\
\hline International Airline & 3 \\
\hline Municipal Transport & $0,5+$ \\
\hline Electricity & $30+$ \\
\hline Telecom 1 & $25+$ \\
\hline Mobile Telecom 1 & 9 \\
\hline Entertainment & 3 \\
\hline Telecom 2 & 1 \\
\hline Mobile Telecom 2 & 1 \\
\hline Very Large Bank & 18 \\
\hline Regional Bank & 1,5 \\
\hline Bank Startup & 0,15 \\
\hline
\end{tabular}




\section{Survey findings}

Findings on SLM profile are summarized onto the three ESLAM dimensions, namely (a) service variables (b) service information systems (c) service organization. The degree of maturity of surveyed organizations has been quantified by a school mark, ranging from 0 to 1 , and results have been reported on radar graphs.

First question is: "Which industries are closer to a mature and complete SLM?" Not surprisingly IT intensive industries as Telecom and Financial services look more mature (Figure 7). Transportation, where IT support is not yet critical, is still in early stages. Further analysis within each industry shows a uniform approach in Telecommunications, even in China. This reflects their global stage of development against the localized one of Transportation and Financial industries.

A further question is: "Are certifications and formalized approaches consistent with a mature SLM stage?" Not surprisingly the finding is positive. Adoption of ITIL (Menken, I. et al., 2009) and/or COBIT (IT Governance
Institute, 2007) is part of the same evolution that drives towards a service level aware management of IT (Figure 8).

Surprisingly, SLM maturity is not related to the outsourcing strategy. Outsourcing, in our sample, reflects the overall business strategy rather than a specific maturity stage of IT management itself (Figure 9).

Finally, the key issue is "What really drives SLM maturity?" Evidence, so far, is very straight. It is the experience years.

Figure 10Figure 10 also shows that after some years, SLM mature organizations tend to invest heavily on technology, to provide information to the whole service management process. Not surprisingly, these organizations have a complete technology architecture that mirrors the framework of Figure 2 However, only in few cases, business outcomes are related to IT business services and, therefore, the business impact of IT services is still a challenge. In some cases we found that business impact is traced ex-post

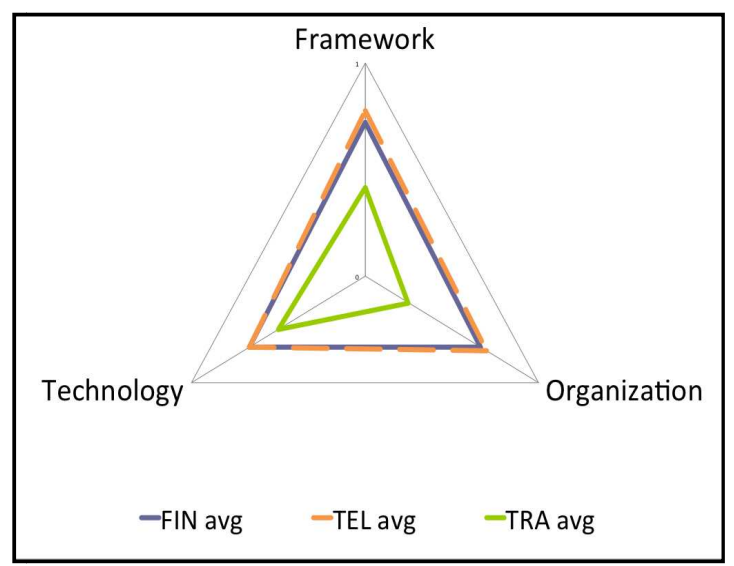

Figure 7 - SLM Maturity across Industries (redesigned from Motta. et al., 2010) 


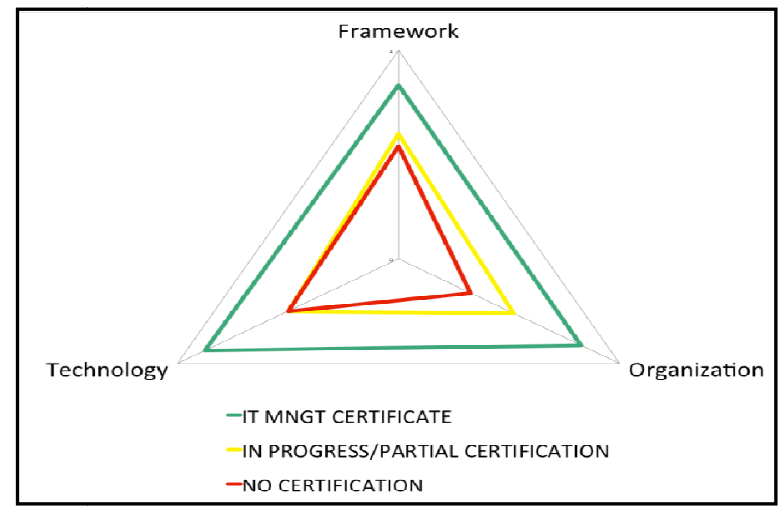

Figure 8 - SLM Maturity versus Management Certification (redesigned from Motta. et al., 2010)

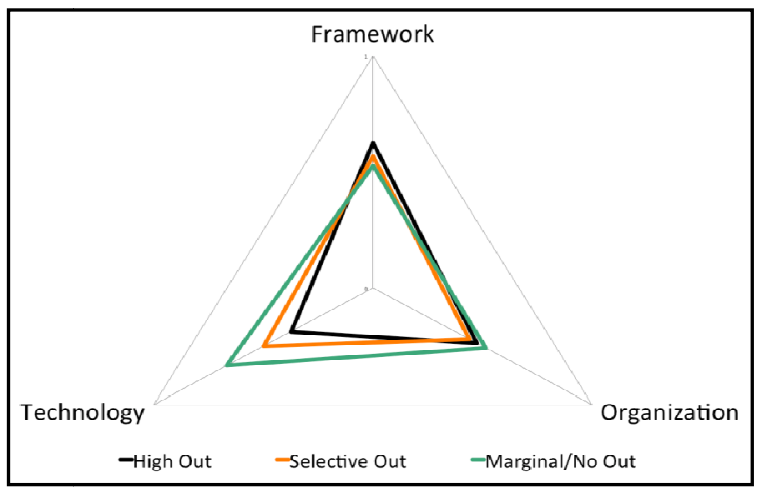

Figure 9 - SLM Maturity versus Outsourcing Strategy (redesigned from Motta. et al., 2010)

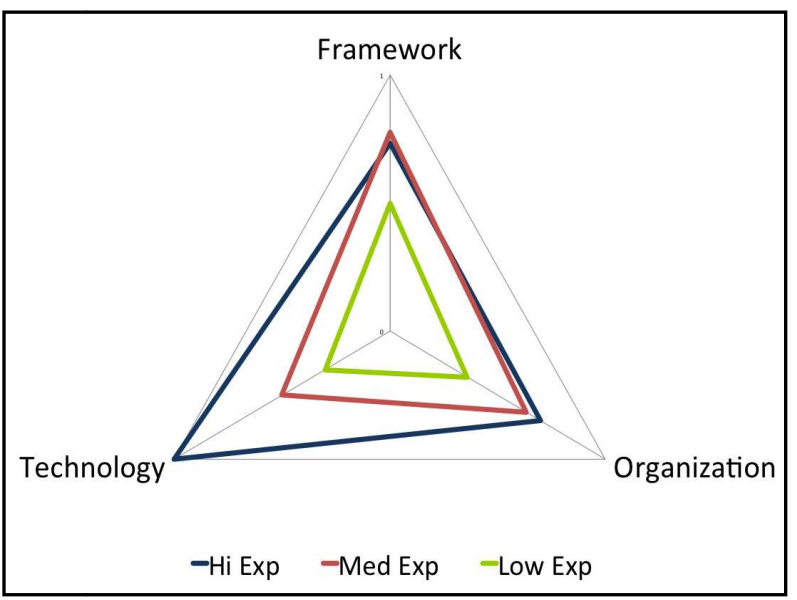

Figure 10 - SLM Maturity versus Years of Experience (redesigned from Motta. et al., 2010) 


\section{Conclusions}

We have presented a survey on SLM practices based on a comprehensive reference grid, that includes service levels, namely organization, variables and information systems. This in-depth survey shows important findings. In IT intensive corporations SLM is a critical element of their IT management, regardless their size. A complete SLM requires years and it is not only matter of money but also of commitment on organizational issues. Complete SLM require a substantial investment in SLM technology that may be a visible percentage of IT budget.

In perspective a critical question is SLM architecture in the cloud computing era. With cloud computing user organizations would not see anymore the service chain that delivers a certain performance. However, providers' SLM, even if they would control only the section of IT service they run, should communicate with both customers' and suppliers' SLM systems. This might require an even more sophisticated SLM system and start a new maturity curve. SLM and cloud computing are precisely the scope of our next research step.

\section{References}

Aib, I., Salle, M., Bartolini, C., Boulmakoul, A., Boutaba, R., \& Pujolle, G. (2006). "Business Aware Policy-Based Management," BusinessDriven IT Management, The First IEEE/IFIP International Workshop on, 7 (7), 55-62.

Anthony, R. N. (1965). "Planning and Control Systems, a Framework for Analysis,” Boston (reprinted numberlesx times).

Barroero, T., Motta, G., Pignatelli, G., Bochicchio, M., Longo, A. \& Raffone, A. (2010). "Aligning IT service Levels and Business Performance: A Case Study," IEEE $S C C$, July 5-10, Miami, Florida, USA.
Bartolini, C., Stefanelli, C. \& Tortonesi, M. (2009). "Business-Impact Analysis and Simulation of Critical Incidents in IT Service Management," proc. IEEE Integrated Management, IM.

Buco, M. J. (2002). "Managing eBusiness on Demand SLA Contracts in Business Terms Using the Cross-SLA Execution Manager SAM," International Symposium on Autonomous Decentralized Systems.

Case, G. (2007) "ITIL v3. Continual Service Improvement," Office of Government Commerce.

Diao, Y. \& Bhattacharya, K. (2008). "Estimating Business Value of IT Services through Process Complexity Analysis," Network Operations and Management Symposium, NOMS, (2008), IEEE , 6 (11), 208-215.

Hiles, A. N. (1994). "Service Level Agreements: Panacea or Pain?," The TQM Magazine, 6 (2), 14-16.

IT Governance Institute (2007). “COBIT $® 4.1$. Framework, Control Objectives, Management Guidelines, Maturity Models.," ISBN 1933284-72-2

Lewis, L. (1999). Service Level Management for Enterprise Networks, Artech House, Inc. Norwood, MA, USA.

Logan, J.C. (2008). "Implementing SLM: Bridging Cultural Gaps and Delivering Business Value through an Automated Service Catalog". [Online]. Computer Associates, CA. [june, 2010] Available: http://www.ca.com/files/technologybriefs/s lm_tech_brief_92008.pdf

Longo, A. \& Motta, G. (2006). "Design Processes for Sustainable Performances: A Model and a Method," Springer, Lecture Notes in Computer Science, 3812. 
Menken, I., Blokdijk, G. \& Malone, T. (2009). ITIL V3 MALC-Managing Across the Lifecycle of IT Services Best Practices Study and Implementation Guide, Emereo Pty Ltd, London, UK.

Microsoft (2008). "Microsoft@ Operations Framework Version 4.0," Microsoft Corporation.

Motta, G., Barroero, T., Galvani, F. \& Longo, A. (2010). "Managing the IT Service Level in Large Organizations: Reference Frameworks and a Survey on Actual Practices". Proceedings of the 15th IBIMA International conference.

Motta, G., Pignatelli, G., Barroero, T. \& Longo A. (2010). "Service Level Analysis Method SLAM," A Framework For IT Service Organizations, 3rd IEEE ICCSIT, July 9 - 11, Chengdu, China.

Raimondi, F., Emmerich, W. \& Skene, J. (2008). "Efficient Online Monitoring of WebService SLAs," Proceedings of the 16th ACM SIGSOFT International Symposium on Foundations of software engineering, pages 170-180, ACM New York, NY, USA

Ribeiro, J. \& Gomes, R. (2009). "IT Governance Using COBIT Implemented in a High Public Educational Institution: A Case Study," Proceedings of the 3rd international conference on European computing conference, pages 41-52, World Scientific and Engineering Academy and Society (WSEAS).

Rudd, C. \& Llyod, V. (2007). "ITIL v3. Service Design," Office of Government Commerce.

Schaaf, T. (2007). "Frameworks for Businessdriven Service Level Management: A Criteriabased Comparison of ITIL and NGOSS," Business-Driven IT Management, BDIM, 2nd IEEE/IFIP International Workshop on, pp.6574.

Schaaf, T. \& Brenner, M. (2008). “On Tool Support for Service Level Management: From Requirements to System Specifications,"
Business-driven IT Management, BDIM, 3rd IEEE/IFIP International Workshop on, 7 (7), 71-80.

Soward, K. \& Lalli, K. (2007). "HP Service Management Framework," Hewlett-Packard Development Company (C).

Taylor, M., Iqbal, M. \& Nieves, M. (2007). "ITIL v3. Service Strategy," Office of Government Commerce.

Toleman, M., Cater-Steel, A., Kissell, B., Chown, R. \& Thompson, M. (2009). "Improving ICT Governance: A Radical Restructure Using CobiT and ITIL," Information Science Reference (IGI Global).

Winniford, M., Conger, S. \& Erickson-Harris, L. (2009). "Confusion in the Ranks: IT Service Management Practice and Terminology," Information Systems Management, 26 (2), 153-163, Taylor \& Francis, Inc. Bristol, PA, USA. 